\title{
GIORGIO AGAMBEN E DANTE ALIGHIERI - REFLEXÕES TEÓRICAS POSSÍVEIS
}

\author{
Silvana de Gaspari \\ Universidade Federal de Santa Catarina
}

Resumo: Estudar a poesia de Dante Alighieri é mais do que estudar somente o medievo e suas representações literárias. É também vislumbrar perspectivas de sobrevivência, que nos trazem até hoje por caminhos nem sempre muito tranquilos, sendo guiados através de rizomas que se organizam e desorganizam em torno de tal autor. Dessa forma, pensando nesse rizoma, na evolução do livro e do mundo, o objetivo deste texto é buscar visualizar Dante como um suscitador de ideias. E Giorgio Agamben aqui é escolhido como interlocutor para a obra do florentino, já que é um filósofo que deixa claro, em muitos de seus textos, que suas reflexões perpassam pela obra do poeta medieval e lhe dão a verdadeira luz da contemporaneidade que ela parece merecer. A partir dessa escolha, serão analisados conceitos como: paródia, comédia e tragédia, contemporaneidade, limbo, profecia e criação, poder e glória, crítica, cânone, sagrado e profano. Partir das reflexões de Giorgio Agamben para pensar Dante nos parece importante não somente pelo fato da abrangência do pensamento deste autor em nosso tempo, mas também pelo fato de ser ele alguém que reflete com o poeta e a partir dele, para construir diversos de seus textos, que se complementam e se renovam, segundo o próprio filósofo, com o tempo.

Palavras-chave: Giorgio Agamben; Dante Alighieri; Divina Comédia; Contemporaneidade.

Inicio este texto com algumas questões que, por mais simples que possam parecer, são necessárias de serem feitas para validarem as ideias que aqui exponho. Por isso pergunto: por que estudar Dante Alighieri até hoje? Seria realmente relevante despender tempo e energia investigando, esmiuçando, retomando as obras de um autor do século XIV?

Para mim, estudar a poesia de Dante Alighieri é mais do que estudar somente o

Esta obra está licenciada sob uma Creative Commons - Atribuição 4.0

\footnotetext{
* Graduada em Letras Português/Italiano pela UNESP-Araraquara, com mestrado em Literatura Italiana pela Universidade de São Paulo e doutorado em Teoria Literária pela Universidade Federal de Santa Catarina. Sua dissertação de mestrado tem como tema central o verismo italiano, com enfoque nos autores Giovanni Verga e Luigi Capuana, e sua tese de doutorado versa sobre a Divina Comédia e sua relação com dois textos apócrifos: Enoque e Isaías. Desde 1992, é professora do Curso de Letras Italiano da Universidade Federal de Santa Catarina, no Departamento de Língua e Literatura Estrangeiras. Tem hoje como foco principal de pesquisa dois projetos: o primeiro, sobre poesia italiana, parte de Dante Alighieri e chega aos poetas contemporâneos, identificando a percepção que estes autores têm do poeta florentino, e, o segundo, investiga o paratexto e está vinculado ao grupo de pesquisa do "Dicionário de Literatura Italiana Traduzida", desenvolvido em parceria entre a UFSC e a USP. Tem diversos livros publicados, entre eles as traduções de $O$ mistério do mal e Pilatos e Jesus, de Giorgio Agamben, em parceria com a professora Patricia Peterle. E-mail: silvanadegaspari@gmail.com.
} 
medievo e suas representações literárias. É também vislumbrar perspectivas de sobrevivência, que nos trazem até hoje por caminhos nem sempre muito tranquilos, sendo guiados através de rizomas que se organizam e se desorganizam em torno de tal autor. Dessa forma, pensando nesses rizomas, na evolução do livro e do mundo, o objetivo deste texto é buscar visualizar Dante como um suscitador de ideias. E é por isso que Giorgio Agamben aqui é escolhido como interlocutor para os escritos desse poeta. O filósofo deixa claro, em muitos de seus textos, que quase sempre suas reflexões perpassam pela obra do poeta medieval e lhe dão a verdadeira luz da contemporaneidade que ela parece merecer.

Desse modo, a partir da escolha dessa parceria, serão analisados, mesmo que muito superficialmente, conceitos como: paródia, comédia e tragédia, contemporaneidade, limbo, profecia e criação, crítica, sagrado e profano. Partir das reflexões de Agamben para pensar Dante, me parece importante não somente pelo fato da abrangência do pensamento do filósofo em nosso tempo, mas também pela perspectiva de ser ele alguém que reflete com o poeta florentino e a partir dele, para construir diversos de seus textos, que se complementam e se renovam com o tempo, segundo as palavras do próprio Agamben.

Assim, dando sequência a esta minha reflexão, gostaria de lhes apresentar uma breve citação:

Louvado como uma das maiores obras da literatura mundial, o Inferno era o
primeiro dos três livros que compunham A Divina Comédia, de Dante Alighieri -
um poema épico de 14.233 versos que descreve sua brutal descida ao mundo
inferior, a jornada pelo Purgatório e, por fim, a chegada ao Paráso. Das três partes
da Comédia - Inferno, Purgatório e Paraíso -, o Inferno é de longe a mais lida e a
mais memorável. Composto por Dante Alighieri no início do século XIV, o Inferno
redefiniu a percepção medieval da danação. Antes dele, a ideia de mundo inferior
nunca havia fascinado as massas de forma tão arrebatadora. Da noite para o dia, a
obra de Dante cristalizou esse conceito abstrato em uma visão nítida e aterrorizante
- visceral, palpável, inesquecível. [...] Retratada ali por Botticelli, essa horrenda
visão dantesca tinha a forma de um funil de sofrimento subterrâneo: um desgraçado
submundo composto de fogo, enxofre, esgoto e monstros, com Satanás em pessoa à
espera lá no centro. (BROWN, 2013, p. 65-66)

O texto citado acima é tirado do livro Inferno, de Dan Brown, lançado em 2013, e que vendeu, em apenas quatro dias, segundo a Folha de São Paulo, 12.600 exemplares no Brasil. Em evidência aqui não está o fato de tal livro ser literatura "boa ou ruim", o que pretendo mostrar é a atualidade e a abrangência da obra do florentino, que insiste e persiste no tempo, principalmente a partir daquela que é considerada uma das maiores obras da literatura ocidental de todos os tempos, a Divina Comédia. Através deste exemplo, e de outros tantos que eu poderia lhes trazer aqui, é que se pode constatar que estudar a poesia dantesca é mais do que estudar somente o medievo e suas representações literárias, é vislumbrar perspectivas 
de sobrevivência. Para Deleuze e Guattari (1995, p. 20):

o livro não é a imagem do mundo segundo uma crença enraizada. Ele faz rizoma com o mundo, há evolução a-paralela do livro e do mundo, o livro assegura a desterritorialização do mundo, mas o mundo opera uma reterritorialização do livro, que se desterritorializa por sua vez em si mesmo no mundo (se ele é disto capaz e se ele pode).

Partindo, então, dessas afirmações, que se encaixam como uma luva no contexto dantesco, busquei elaborar aqui uma breve "viagem", que nos levará, ao final, a construir nossos próprios itinerários de viagem, viagem pelo conhecimento e pela descoberta, guiados por Agamben, através das visões de Dante.

Assim, pensando em Dante especificamente, busquei evidenciar que um dos principais fatores que fazem desse autor um escritor atual, está justamente no fato de ele ter colocado o homem no centro de tudo e ter descrito suas fraquezas, angústias, anseios e misérias. Construindo a ponte com Agamben, impossível não pensar no que é ser contemporâneo. O próprio filósofo, no início de seu texto, nos coloca algumas questões e diz: "A pergunta que gostaria de escrever no limiar deste seminário é: 'De quem e do que somos contemporâneos? E, antes de tudo, o que significa ser contemporâneo?'” (AGAMBEN, 2009, p. 57)

E é o próprio autor quem nos responde: “O 'tempo' do nosso seminário é a contemporaneidade, e isso exige ser contemporâneo dos textos e dos autores que se examinam. Tanto o seu grau quanto o seu êxito serão medidos pela sua - pela nossa capacidade de estar à altura dessa exigência." (AGAMBEN, 2009, p. 57).

Ainda citando o autor:

A contemporaneidade, portanto, é uma singular relação com o próprio tempo, que adere a este e, ao mesmo tempo, dele toma distâncias; mais precisamente, essa é a relação com o tempo que a este adere através de uma dissociação e um anacronismo. Aqueles que coincidem muito plenamente com a época, que em todos os aspectos a esta aderem perfeitamente, não são contemporâneos porque, exatamente por isso, não conseguem vê-la, não podem manter fixo o olhar sobre ela. (AGAMBEN, 2009, p. 59)

Prosseguindo, não satisfeito com sua definição primeira, Agamben nos oferece uma segunda interpretação do que ele entende por contemporâneo:

[...] contemporâneo é aquele que mantém fixo o olhar no seu tempo, para nele perceber não as luzes, mas o escuro. Todos os tempos são, para quem deles experimenta contemporaneidade, obscuros. Contemporâneo é, justamente, aquele que sabe ver essa obscuridade, que é capaz de escrever mergulhando a pena nas trevas do presente. (AGAMBEN, 2009, p. 62-63)

Quase no final de seu ensaio "O que é o contemporâneo", o filósofo nos brinda com Anu. Lit., Florianópolis, v. 22, n. 2, p. 62-73, 2017. ISSNe 2175-7917 
mais uma definição, mais do que oportuna para este momento:

Isso significa que o contemporâneo não é apenas aquele que, percebendo o escuro do presente, nele apreende a resoluta luz; é também aquele que, dividindo e interpolando o tempo, está à altura de transformá-lo e de colocá-lo em relação com os outros tempos, de nele ler de modo inédito a história, de "citá-la" segundo uma necessidade que não provém de maneira nenhuma do seu arbítrio, mas de uma exigência à qual ele não pode responder. (AGAMBEN, 2009, p. 72)

Apesar de, especificamente neste ensaio, Agamben não citar Dante ou recorrer às suas obras como exemplo de suas reflexões, é impossível não pensar no poeta enquanto exemplo nato da contemporaneidade proposta ali, já que Dante buscava, na Idade Média, seu tempo cronológico, um homem livre, tanto nas suas escolhas sobre a terra como na sua vida espiritual, liberto do poder teocêntrico da época.

Agamben, falando sobre a liberdade do poeta, sobre a contemporaneidade e sobre a "fratura entre os tempos", que, de meu ponto de vista, se caracteriza em Dante por ser ele um homem medieval vivendo no limiar dos tempos modernos, diagnostica ser contemporâneo o perceber no escuro do presente a luz das galáxias distantes, que tentam, mas não conseguem, nos alcançar. Por isso, diz ele que os contemporâneos são muito difíceis de serem encontrados. Por isso, assumir a atitude de se cegar para o presente para vislumbrar o futuro, é um ato de coragem, já que se deve manter os olhos fixos no escuro para se perceber a luz que, mesmo quando dirigida a nós, de nós se distancia. Por essa perspectiva, Dante, na obra $O$ Banquete - tradução em português do Convivio - se define como alguém que recolhe as migalhas deixadas pelos grandes mestres do pensamento e as transmite aos outros.

Esse homem, ao se atribuir a missão de transmitir o que vê e o que ouve aos que estão por vir, se impregna de um caráter profético tão discutido já pelos estudiosos de sua vida e obra. Esse caráter profético também se vincula ao fato de a Divina Comédia apresentar, assim como os livros proféticos judaicos, uma relação entre investida, ameaça e renovação. Ou seja, por um lado o autor denuncia todas as iniquidades cometidas e que justificariam a ira de Deus, por outro, ele espera, com isso, levar as pessoas ao arrependimento, o que poderia prevenir as consequências desta ira. Dante Milano comenta que:

Na “Commedia” há uma poesia que não é só de Dante. É do mundo, da humanidade. Isto diferencia os Antigos dos Modernos. Estes tiram tudo de si. Aqueles captavam tudo - de tudo e de todos -, do que havia e do que tinha havido, do passado recente e remoto, de toda a experiência e sabedoria acumulada pelos séculos. E retransmitiam tudo que aprendiam: história, ciência, religião, fatos, gestos, ditos memoráveis. Todo poeta antigo ensinava o que sabia, vulgarizava a sua erudição, imitava o que havia de melhor nos seus antecessores, o que era digno de perpetuidade e de ser transmitido de um idioma a outro, de geração a geração, para que nada se perdesse e tudo se salvasse, do que há de grande no mundo. (MILANO, 1965, p. 112) 
Aí outro ponto de discussão em Agamben se evidencia: criação e salvação. $O$ filósofo, em Nudez, no capítulo "Criação e Salvação", afirma serem esses dois conceitos indissociáveis: o profeta que salva e o anjo que cria. Para ele:

\begin{abstract}
Na cultura da época moderna, a filosofia e a crítica herdaram a obra profética da salvação (que na esfera sagrada fora antes confiada às exegeses); poesia, técnica e arte, à obra angélica da criação. No processo de secularização da tradição religiosa, todavia, perderam progressivamente toda a memória da relação que, naquela, às ligava tão intimamente... Onde, outrora, sabia dar conta da sua poesia ("Abri-la pela prosa" [Aprirla per prosa], dizia Dante) e o crítico era também poeta, o crítico, que perdeu a obra da criação, vinga-se sobre esta pretendendo julgá-la; o poeta, que já não sabe salvar a sua obra, compensa esta incapacidade entregando-se cegamente à frivolidade do anjo. O certo é que as duas obras, na aparência, autônomas e estranhas, são, na realidade, os dois rostos de um poder divino e, pelo menos no profeta, coincidem num único ser. A obra da criação, na verdade, é só uma centelha que se soltou da obra profética da salvação, e a obra da salvação é só um fragmento da criação angélica que se tornou consciente de si próprio. O profeta é um anjo que, no próprio impulso que o incita à acção, descobre subitamente na sua carne viva o ímpeto de uma exigência diferente. (AGAMBEN, 2010, p. 13-14)
\end{abstract}

Nosso poeta, profeta e anjo, cunhados na mesma carne e na mesma alma, e mencionado diretamente por Agamben no texto acima, se sentia um ser humano investido de uma missão profética, para a qual ele havia sido chamado por Deus. Ele dizia que seu objetivo era escrever uma obra que preparasse o caminho da reforma da Igreja, segundo seus próprios princípios, tão necessária e próxima, mediante uma narrativa que mostrasse aos homens os terríveis efeitos da depravação, nascida pelo contraste entre os guias espirituais, estabelecidos por Deus para o governo espiritual da humanidade, e a corrupção da igreja, desejosa de riqueza e poder. Tal obra, a Divina Comédia, deveria, ao mesmo tempo, ensinar os meios e anunciar os instrumentos da muito próxima redenção dos homens.

A partir de tal missão, que ele mesmo se delegou, o poeta pôde muito bem "se vestir" de profeta, que fala em nome de Deus, mas não deixa de ser poeta, e, enquanto tal, deve conhecer a distância entre o que é texto e o que é divino, entre criação e salvação, mesmo podendo exercer os dois papéis com muita precisão. Para Agamben (2010, p. 9), por muito tempo, os profetas desapareceram da história do Ocidente. Se é verdade que não se pode entender o judaísmo sem entender a figura do nabi, ocupando os livros proféticos um lugar central na Bíblia, é também verdade que, dentro do judaísmo, existem forças que operam no sentido de limitar o exercício e o tempo do profetismo. Com o mesmo sentido, o cristianismo reconhece a função essencial da profecia e constrói a relação entre antigo e novo testamento a partir dela. No islã ou no judaísmo, a obra da salvação é atribuída a uma criatura: ou o profeta ou o messias. Maravilhoso é, aqui, que não ao criador, mas a uma criatura, seja confiada a redenção do criado. Isso significa que criação e salvação continuam, de todo modo, estranhas 
uma à outra, que não é aquilo que em nós é princípio de criação que poderá salvar aquilo que produzimos.

Isso significa que a salvar o mundo não será o poder angelical espiritual, com o qual os homens produzem suas obras, mas o mais humilde e corpóreo, que compete com ele enquanto criatura. Isso significa que, no profeta, os dois poderes coincidem, que o titular da obra da salvação também pertence à criação. $\mathrm{O}$ anjo que chora se faz profeta, o lamento do poeta sobre a criação torna-se profecia crítica. A obra da redenção, então, é eterna, diferente da obra da criação. Por isso pode-se dizer que o conhecimento supremo é o que chega muito tarde, quando não precisamos mais dele. Pensando em profecia, segundo o filósofo, a visão dantesca seria talvez, para o poeta, pura ficção poética, algo semelhante a um romance teológico, ou, como ele mesmo dizia no Banquete, uma grande mentira escondida sob uma verdade que ainda deveria ser descoberta, uma verdadeira profecia destinada a salvar a criação.

Pensando, então, em ficção poética, por que não encarar a Comédia como uma grande paródia? Em Categorias Italianas, no capítulo "Paródia”, Agamben (2014, p. 160) define o que ele mesmo identifica como os dois traços canônicos deste gênero literário: "a dependência de um modelo pré-existente, transformado de sério em cômico, e a manutenção de elementos formais nos quais são inseridos conteúdos novos e incongruentes". O capítulo percorre, à moda agambeniana, a história do conceito de paródia e nos brinda com referências e informações preciosíssimas, que dão a esse termo mais do que aquilo que, muito superficialmente, geralmente conhecemos. Uma delas é que:

\footnotetext{
A leitura dos tratados teológicos sobre o limbo revela, sem sombra de dúvidas, que os padres da igreja concebiam o 'primeiro círculo' como uma paródia ao mesmo tempo do paraíso e do inferno, tanto da beatitude quanto da danação. Do paraíso, na medida em que este abriga criaturas - crianças mortas antes do batismo ou pagãos justos que não puderam conhecê-lo - que são, como os beatos, inocentes, e, todavia, trazem consigo o pecado original. $\mathrm{O}$ elemento mais ironicamente paródico, entretanto, diz respeito ao inferno. Segundo os teólogos, a punição aos habitantes do limbo não pode ser uma pena aflitiva, como aquela aplicada aos danados, mas somente uma pena privativa, que consiste na perpétua carência da visão de Deus. [...] Em um sentido particular, toda a tradição da literatura italiana está sob o signo da paródia. Gorni mostrou como a paródia (ainda que na forma séria) é um constituinte essencial do estilo dantesco, que busca produzir um duplo com quase a mesma dignidade em relação às passagens da Sagrada Escritura que reproduz. Mas a presença da instância paródica na literatura italiana é ainda mais íntima. (AGAMBEN, 2014, p. 165)
}

E por aí prossegue o filósofo, argumentando em torno da paródia e sua presença na literatura italiana, e não deixando de ter no "mestre da idade média" seu ponto máximo de referência. Especificamente sobre o limbo, no volume A comunidade que vem, Agamben 
dedica uma pequena reflexão sobre este "primeiro círculo" que vale a pena ser lida. São duas páginas da mais densa reflexão filosófica sobre este termo, que mantém a vida em suspenso, tanto no tempo quanto no espaço, "Como cartas sem destinatário, estes ressuscitados ficaram sem destino. Nem bem-aventurados como os eleitos, nem desesperados como os condenados, eles estão cheios de uma alegria que não pode chegar ao fim." (AGAMBEN, 1993, p. 14)

Agora, retomando os constituintes da paródia, para Dante, as imagens apocalípticas, apresentadas em Ezequiel, Daniel e, principalmente, João, não eram somente alegoria, mas também uma comparação implícita com o mundo no qual ele vivia. Mesmo que as referências ao Gênesis e aos Salmos sejam mais frequentes ao longo do poema, é bem claro que o discurso profético é um elemento constitutivo muito forte da Divina Comédia, principalmente quando pensado através dos elementos paródicos que Agamben nos apresenta. É por isso que se torna possível ver a teologia não como uma regra e sim como um recurso entre tantos outros usados por Dante. O autor, também na figura de narrador e personagem, o guia Virgílio e a amada Beatriz, são representações extraordinárias não de algum código teológico, mas de uma história ou mito intensamente pessoal: ousado, ambicioso e declaradamente profético.

Além do tom paródico que se observa na Comédia, o poeta é também um experimentador de diversos gêneros poéticos, e este exercício lhe prepara o caminho para a Divina Comédia, na qual se utiliza do trágico, do cômico e ainda de uma pluralidade de linguagens. É por isso que a Divina Comédia não representa um novo gênero, tão original e extraordinário que Dante tenha criado do nada. Na realidade, o grande mérito do autor está no fato de ele ter reunido vários conceitos, vários pensamentos que estavam adormecidos por trás de formas literárias já existentes como: lendas, visões, tratados, sonetos, canções e outros tantos gêneros literários já divulgados na época. A substância de seu "gênero inovador" está na tradição popular criada em torno dos segredos da alma, e é esta imagem que o autor busca representar.

Seguindo meu percurso, quase que frenético por alguns dos pensamentos e conceitos estudados por Agamben, já que a ideia de paródia perpassa o conceito de comédia, passemos, então, a pensar no título da viagem dantesca. A ideia do título, Comédia, segundo alguns estudiosos, nasceu no momento em que o poeta se voltou para os clássicos antigos para obter seu guia e iluminação poética. O epíteto "divina" foi acrescentado na edição veneziana de 1555, impressa por Gabriele Giolito e revisada por Ludovico Dolce, além de ter sido usada, anteriormente, por Giovanni Boccaccio. Muitas outras razões teve Dante para definir como comédia seu próprio texto, visto que comédia, neste caso, em contraste com tragédia, seria a 
obra cuja linguagem é totalmente inadequada para exprimir a realidade que ele quer representar. Em Ferrucci, lemos que:

A tragédia divina foi traçada em um misterioso alfabeto não escrito e recitado pelos anjos ao redor de Deus; para falar do mundo sobrenatural, a Dante só resta a linguagem humana que, aos olhos e ouvidos de Deus não pode parecer outro que Comédia, heroica e patética paródia da Tragédia altíssima e não escrita. (FERRUCCI, 2007, p. 140). ${ }^{1}$

Já em Agamben (2014, p.15), falar sobre o problema da comédia é

[...]discutir a situação crítica de um evento que, cronologicamente cumprido no início do século XIV, exerceu sobre a cultura italiana uma influência a tal ponto profunda que é possível dizer que ele ainda não deixou de acontecer. Trata-se da decisão de um poeta de abandonar o próprio projeto poético "trágico" em prol de um poema "cômico". Essa decisão se traduz em um célebre incipit, que uma carta do autor enuncia deste modo: Incipit comoedia Dantis Alagherii florentini natione non moribus [Começa a comédia de Dante Alighieri, florentino de nascimento e não de costumes]. A mudança, de que essas palavras dão conta, é em tão pouca medida uma questão interna da crítica dantesca que se pode afirmar que nela toma forma, pela primeira vez, a figura de um dos traços mais característicos da cultura italiana: a sua essencial pertinência à esfera cômica e a sua consequente refutação da tragédia.

Passando por autores como Auerbach, Benvenuto da Imola, Boccaccio, Boecio, Singleton e tantos outros estudiosos dantescos, além do próprio Dante, como anjo salvador de sua criação, através da Epístola a Cangrande della Scala, o filósofo desenvolve seu ensaio com a maestria de sempre.

Para Agamben, o autor usa o termo "comédia" ainda no sentido que ele tem para a cultura medieval. Dizendo comédia, ele não queria se referir ao teatro ou a um tipo de espetáculo, mas às distinções de língua e estilo elaboradas pela retórica. Ele define a comédia como: um gênero de narração poética. Na concepção aristotélica, a comédia procura imitar os homens piores e a tragédia melhores do que, em geral, eles são. Historicamente falando, Agamben (2014, p. 18) afirma:

É certamente possível ver na sua escolha uma confirmação daquela posição historicamente atrasada sobre a qual tanto se insistiu. Isso porque, para além do projeto trágico dos poetas de amor que ele tinha compartilhado, na cultura de seu tempo já estavam em ação os fermentos, dos quais na Itália se fez intérprete Mussato, que teriam levado, com base na descoberta do caráter trágico da história, à reafirmação da tragédia na Idade Moderna.

A escolha do título Comédia foi e ainda é um problema para a crítica dantesca moderna. Aqui partimos do princípio de que a escolha de Dante não foi negligente, mas

\footnotetext{
1 “La tragedia divina è stata tracciata in um misterioso alfabeto non scritto e recitato dagli angeli intorno a Dio; per parlare del mondo sovrannaturale a Dante nons resta che il linguaggio umano, che agli occhi e orecchi di Dio non può apparire che Commedia, eroica e patetica parodia della sua Tragedia altissima e non scritta." Tradução nossa.
} 
atentamente pensada. Se recuperarmos a própria fala de Dante sobre esta escolha, veremos que ela foi muito bem fundamentada. A escolha do título Comédia implica em uma ruptura, uma reviravolta no seu próprio itinerário poético, uma verdadeira "mudança categórica", consciente e vital. Há em Dante, com esta escolha semântica, uma intenção maior que a percebida pela crítica moderna. A definição que a carta a Cangrande della Scala dá para a oposição entre trágico/cômico foi considerada até agora sem se pensar em seu contexto. $\mathrm{O}$ fím cômico ou trágico só pode ser definido em relação a seu sujeito; referindo-se à salvação ou à perdição do homem. Muito distante de ser uma escolha insignificante, o título carrega uma tomada de posição em relação a uma questão essencial: a culpa ou a inocência do homem diante da justiça divina. Traços que se mantêm intactos até hoje a partir de nossa herança judaico/cristã.

O início terrível e o fim cheio de graça querem significar que o homem, inicialmente culpado, chega ao fim inocente de seus pecados. No centro da consciência cômica de Dante estão a inocência natural e a responsabilidade pessoal. Quem faz a viagem não é um Eu, no sentido moderno, mas uma conjugação de persona e natura. É a concepção cômica da criatura humana dividida em natureza inocente e pessoa culpada, que deixou Dante como herança à cultura italiana.

Para Dante autor, o termo comédia refere-se ainda a uma obra que começa infeliz e termina em felicidade. Por isso a narrativa começa no Inferno, onde se encontram as almas atormentadas e se encerra no Paraíso, lugar das almas abençoadas, abrindo a possibilidade de salvação para o homem enquanto indivíduo e para os homens em geral.

O fascínio do reino do oltretomba dantesco não está no que se pode revelar, na visão que se lhe terá revelado, mas na vivência do sentir. A interpretação do poema se faz mais rica quando feita a partir dos instrumentos artísticos utilizados pelo próprio autor e que foram amadurecendo com o tempo, através da reflexão sobre suas premissas teóricas, com o esclarecimento e o distanciar-se das questões de cunho polêmico, já que a Divina Comédia tem um narrador que também é personagem da ação: é o herói que conta sua própria história.

História de herói sobre a qual diversos documentos e testemunhos nos indicam que a Comédia penetrou amplamente também em ambientes de cultura não especializada, inclusive entre os mercantes e os artesãos. Talvez isso se deva ao fato que, à inabalável fé na vida do oltretomba, como único e verdadeiro caminho, unia-se, na obra de Dante, o forte sentimento das coisas do mundo. Por isso, o acontecimento terreno de cada indivíduo não podia ser visto como uma realidade definitiva e única, mas como uma ligação imediata entre céu e terra, 
determinada pelo divino, que, futuramente, seria a realidade verdadeira. Ligação, ligare, religare. Em "Elogio da profanação":

O termo religio, segundo uma etimologia ao mesmo tempo insípida e inexata, não deriva de religare (o que liga e une o humano e o divino), mas de relegere, que indica a atitude de escrúpulo e de atenção que deve caracterizar as relações com os deuses, a inquieta hesitação (o "reler") perante as formas - e as fórmulas - que se devem observar a fim de respeitar a separação entre o sagrado e o profano. (AGAMBEN, 2007, p. 66)

Céu e terra, sagrado e profano, Deus e a humanidade, realidade e ficção que se unem e, ao mesmo tempo, se distanciam, numa releitura do mundo profano e sua relação com o sagrado.

\footnotetext{
Os juristas romanos sabiam perfeitamente o que significa 'profanar'. Sagradas ou religiosas eram as coisas que de algum modo pertenciam aos deuses. Como tais [sagradas], elas eram subtraídas ao livre uso e ao comércio dos homens, não podiam ser vendidas nem dadas como fiança, nem cedidas em usofruto ou gravadas de servidão" (AGAMBEN, 2007, p. 65).
}

Tirá-las da esfera do divino e compartilhá-las com a humanidade foi a tarefa que o herói se impôs em sua epopeia. Ato que o definiria sacrílego como "era todo aquele que violasse ou transgredisse esta sua especial indisponibilidade, que as reservava exclusivamente aos deuses celestes [...] ou infernais [...].” (AGAMBEN, 2007, p. 65).

Porém, deixando de lado o sagrado, a Divina Comédia continua sendo a descrição do estado em que as almas se encontram após a morte, seu tema continua sendo o da vida sobre a terra e todos os acontecimentos que a circundam. Isso é pertinente se se pensa que Dante acreditava realmente na convivência harmoniosa entre a história da salvação e o poder secular, exercido pelos imperadores e papas. Mas ele deixa claro, principalmente na Monarquia, que, para que isso ocorresse, o poder temporal não deveria ser exercido pelo papa, assim como o poder espiritual não era pressuposto do imperador.

E, mais do que isso, o poeta não acreditava somente na convivência pacífica entre poder secular e religioso, mas também na convivência de falas, histórias que se fizeram por si, que se utilizavam das vozes de seus próprios protagonistas para serem contadas. Histórias que teceram a rede de histórias que, sob a justificativa da salvação, ou da perdição para os habitantes do inferno, construíram o percurso da humanidade perdida entre poder e glória.

Aqui, mais do que oportunamente, encerro o presente artigo lançando mão de um breve texto que Agamben publica em Categorias Italianas, intitulado "A caça da língua". Nele, o filósofo nos apresenta Nemrod, o construtor da Torre de Babel e o caracteriza como caçador. Dante o coloca no canto XXXI do Inferno, onde ele, apesar de falar, não é entendido 
por ninguém, castigo eterno por ter desejado que sua torre alcançasse a morada de Deus. Mas,

o que Nemrod caçou? E por que a sua caça é 'contra Deus'? Se a punição de Babel foi a confusão das línguas, é provável que a caça de Nemrod tivesse a ver com um aperfeiçoamento artificial da única língua dos homens, que devia abrir à razão um poder sem limites. (AGAMBEN, 2014, 193).

Nesse breve ensaio, que marca a aproximação de Dante e Caproni, o filósofo diz que a pesquisa sobre a língua poética se faz mortal. Assim,

\begin{abstract}
Os dois aspectos da linguagem humana (a nomeação de Nemrod e a amorosa busca do poeta) tornaram-se então indistinguíveis, e a caça é de fato uma experiência mortal, cuja presa - a palavra - é uma besta que, diz Caproni, "vivifica e mata", e que, "mansa e atroz", talvez volte uma última vez a vestir o manto pintado da pantera dantesca (mas uma "pantera nebulosa" e "suicida"). (AGAMBEN, 2014, 193)
\end{abstract}

Que a morte aqui represente só o recomeço de uma poesia que, "criada" por Dante e "salva" por tantos outros, assim como por Caproni, possa nos vivificar e recriar em nós o verdadeiro gesto divino do Verbo que se faz vida, a real criação de tudo.

\title{
Referências
}

AGAMBEN, Giorgio. A comunidade que vem. Lisboa, Portugal: Presença, 1993.

. Categorias Italianas - Estudos de poética e literatura. Florianópolis: UFSC, 2014.

. Nudez. Tradução Miguel Serras Pereira. Lisboa: Relógio D’Água Editores, 2010.

. O que é o contemporâneo e outros ensaios. Tradução Vinicius Nicastro Honesko.

Chapeco: Argos, 2009.

2007.

. Profanações. Tradução e apresentação Selvino José Assmann. São Paulo: Boitempo,

BROWN, Dan. Inferno. São Paulo, Brasil: Arqueiro, 2013.

DELEUZE, Gilles; GUATTARI, Félix. Mil Platôs, capitalismo e esquizofrenia, v. 1. Tradução Antonio Guerra Neto e Célia Pinto Costa. Rio de Janeiro: Ed. 34, 1995.

FERRUCCI, Franco. Dante. Lo stupore e l'ordine. Napoli: Liguori Editore, 2007

MILANO, Dante. "O meu Dante" in: LISBOA, H. et al. O meu Dante São Paulo: Instituto Cultural Ítalo-brasileiro, 1965.

\section{Giorgio Agamben and Dante Alighieri - possible theoretical reflections}

Abstract: Studying the Dante Alighieri's poetry is more important than studying only the medieval era and its literary representations; it is also to glimpse survival perspective, which is brought to us by ways that are not always very calm, being guided through rhizomes that organize and disorganize themselves around the author. Thus, thinking of this rhizome, on 
evolution of the book and of the world, the aim of this text is to view Dante as an idea originator. Giorgio Agamben is chosen as an interlocutor of the Florentine work, because he is a philosopher who shows his reflection in his most texts regarding medieval poetry work and it gives him the true light of contemporaneity that it seems to deserve. From this choice, concepts such as parody, comedy and tragedy, contemporaneity, limbo, prophecy and creation, power and glory, criticism, canon, sacred, and profane will be analyzed. Thinking regarding Dante from Giorgio Agamben's reflections seems to be important, not only due to his thought span on actuality, but also to be someone that reflects Dante and for him to compose Giorgio many texts, which complement and renew themselves over time, according to the philosopher.

Keywords: Giogio Agamben; Dante Alighieri; Divina Comedia; Contemporaneity.

Recebido em: $26 / 10 / 2017$

Aceito em: 03/11/2017

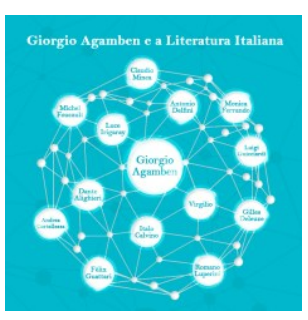

